\title{
A luta segue por novos caminhos
}

\author{
EntreVISTA DE Júlio SANTANa BRAgA
}

$\mathrm{N}$

A APRESENTAÇÃo de matérias sobre a população negra da Bahia e a evolução de sua luta contra a desigualdade e o preconceito racial, ESTU Dos

A VAN ÇA D os entrevistou Júlio Santana Braga, professor da U niversidade Federal da Bahia (U FBa). Seu depoimento é valioso porque ele, como antropólogo, realizou pesquisas durante dez anos na África e é uma das figuras mais expressivas dos candomblés em Salvador, além de auxiliar as autoridades baianas em seu relacionamento com as organizações de afro-descendentes. A entrevista foi obtida num intervalo de uma reunião do Conselho Estadual de Cultura, no dia 12 de fevereiro, em Salvador.

ESTUd os A VA N ÇA D os - O que está acontecendo aqui, em Salvador, para que o preconceito racial na sociedade seja efetivamente superado?

Júlio Santana Braga - D everíamos pensar um pouco sobre a história de uma atitude e de uma ação contra as formas mais diferenciadas de preconceito racial. N esse sentido, há uma revolução que surgiu na Bahia - e principalmente em Salvador - de movimentos organizados que lutam pela erradicação das diversas formas desse preconceito.

O preconceito racial na Bahia é muito grande, até porque a população negra é também muito grande. Poderia ser o inverso, mas o fato de a maioria da população ser negra acentua ainda mais os níveis de preconceito. A partir da década de 1970 teve início uma reviravolta na sociedade, que, histórica e erradamente, era considerada uma minoria étnica, quando os negros eram e são a maioria na população baiana.

Esses grupos nasceram, em parte, devido a vontade de se colocarem no grande leque das atividades lúdicas da cidade. M as logo depois se constituíram em núcleos que procuram os mecanismos que podem ser acionados para uma revisão da desigualdade na Bahia. D ois grupos, criados quase no mesmo momento, são importantes: o O lodum e o Ilê Ayê, em 1974, mas que somente passaram a se expressar como valor cultural em 1976. Eles tiveram a capacidade de fazer com que uma parcela da grande população baiana passasse a avaliar a situação do negro na sociedade, assim como também a equacionar os mecanismos para que essa situação fosse revista. $\mathrm{N}$ ão tenho elementos para dizer se isso foi conseguido ou não. 
$\mathrm{N}$ a verdade, houve alterações consideráveis no que se refere a se ver o negro não como um elemento auxiliar da sociedade e da cultura, mas como um elemento importante e, sobretudo, diferenciado de tudo o que acontece na Bahia, do ponto de vista de uma cultura "popular". Esses grupos expressam, sobretudo, uma novidade na história dessa população, porque deixaram de ser participantes das grandes promoções artísticas e culturais da Bahia a fim de serem seus promotores. E sse é um diferencial muito grande, porque eles estão conscientes desses valores e também estão se apoderando deles. Pois são eles próprios que constroem os instrumentos com os quais trabalham.

\section{O comportamento das autoridades}

Acredito que, atualmente, estejamos num momento positivo. I sso porque podemos repensar essa situação, não só da po pulação negra na Bahia, a partir de seus movimentos, mas também incitar o governo a repensá-la.

Temos hoje uma Secretaria Estadual de Cultura e Turismo, administrada pelo dr. Paulo Gaudenzi, etambém um órgão no município de Salvador (a Secretaria da Reparação), que têm uma maneira diferenciada de pensar os valores étnicos. $O$ conviteque me foi feito pelo governador dr. Paulo Souto, para participar do Conselho Estadual de Cultura, e a tantos outros ligados à cultura popular, parece expressar o desejo institucional de se ter, nos centros de reflexão, pessoas que trabalham, no dia-a-dia, com temas ligados às mais diferentes áreas da cultura baiana, onde a cultura afro-brasileira tem papel significativo. Essa instituição sempre cuidou, preferencialmente, das discussões voltadas para a cultura acadêmica, a cultura de elite.

Trouxemos para o Conselho a informação - e avaliação - do 25 C oncurso da Beleza N egra, promovido pelo I lêA yê em seu 30 ano. 0 grande diferencial da Bahia (do ponto de vista cultural, com reflexos na economia, através do turismo) é sua população negra e suas múltiplas manifestações culturais.

Esse concurso é um momento marcante na história da cidade. U ma festa assistida por mais de quatro mil pessoas que tem, em sua maioria, dificuldades para pagar vinte ou vinte e cinco reais por um ingresso.

É importante dizer que não se trata de um espetáculo de dança, poisé um espetáculo de etnicidade, de identidade. $E$ aquela multidão não éformada apenas de espectadores; são atores de uma mesma encenação de etnicidade, de valorização de uma estética negra, refletida na beleza das dançarinas, da percussão, dos cânticos do Ilê, todos eles clamando inclusão, justiça social e igualdade entre os homens.

Por isso sou otimista. Penso que a sociedade negra está numa direção boa, no sentido de projetar-se cada vez mais, por meio de suas instituições e de seus valores culturais, que foram e serão os diferenciais na cultura baiana. A cultura negra está presente em todos os setores da sociedade baiana e tudo o que acontece na Bahia tem uma cabeça negra ou mestiça fazendo esse diferencial. 


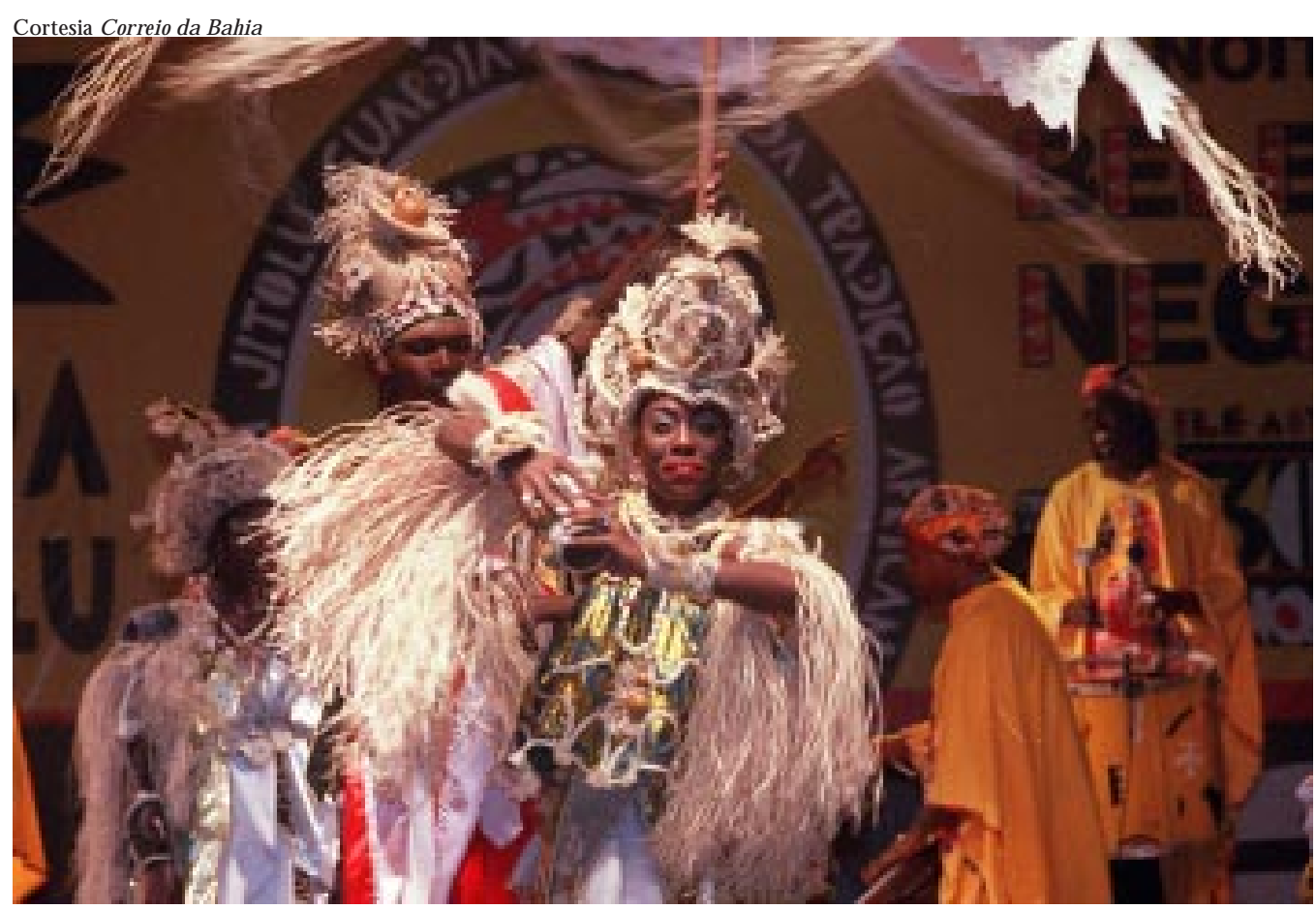

A D eusa deÉbano - Fotografia de Talita Bezerra de Amorim, 22 anos, que venceu a 250 edição do concurso da Beleza N egra do I lê Aiyê, realizado no último dia 6 de fevereiro, em Salvador. Talita é estudante universitária, no curso de $\mathrm{H}$ istória e vive engajada em trabalhos sociais, onde mora, em I tapuã. Ela concorreu com outras 83 candidatas ao título de rainha desse bloco afro, fundado em 1974. N este ano, o concurso prestou uma homenagem à lider espiritual do I lê, $\mathrm{H}$ ilda J itolu. (Informe Cor reio da Bahia, 9/ 2/ 2004)

\section{U $m$ antropólogo no candomblé}

E STU D os A va N ç A D os - G ostaria que o senhor falasse sobre a relação existente entre sua formação acadêmica, como antropólogo, e sua ligação com o candomblé.

Júlio Santana Braga - Sempre deixo de lado essa questão. M as ela é importante para enfatizar o que éo estar presentede um doutor em antropologia, quando, ao mesmo tempo, se é um homem do povo, absolutamente integrado nas comunidades religiosas afro-brasileiras, especialmente nos candomblés da Bahia. Se eu fosse apenas o antropólogo que escreveu dez livros, com pós-doutorado em Boston e na Faculdade de Ciências H umanas de E strasburgo, talvez não estivesse assessorando o Secretário de Cultura e Turismo do Estado, nem estivesse na honrada condição de membro do Conselho de Cultura. Trago para o epicentro dessas discussões uma experiência que não é puramente acadêmica. $\mathrm{N}$ ão sei se você sabe, mas moro num candomblé. Tenho um apartamento, mas o alugo para manter a comunidade religiosa na qual sou sacerdote. Trago uma experiência que às vezes é exótica, mas meu trabalho é exatamente fazer pensar que não há exotismo algum em ser da comunidade e doutor em antropologia. 
Estud os A VA N ÇA D os - O candomblé foi muito perseguido. Pergunto: hoje o candomblé ainda é o mesmo que resistiu à perseguição policial? Para se legalizar, ele perdeu aquele tom subversivo?

Júlio Santana Braga - Escrevi um livro sobre isso, chamado de $\mathrm{N}$ a gamela dofeitiço, em que realizo um estudo da repressão policial ao candomblé. 0 período em que mais houve essa perseguição foi na década de 1920, destacando-se aí 0 delegado Pedro Azevedo Gordilho, que foi o grande inquisidor da cultura religiosa. Ele realizou uma perseguição que não refletia somente a cabeça de um delegado de polícia, mas sim de toda a sociedade baiana. $\mathrm{N}$ aquela década, era a da segunda geração posterior à abolição da escravatura, e o candomblé era uma espécie de tormento para todos os padrões culturais na Bahia. $\mathrm{H}$ á um dado ponderável nisso tudo: as grandes correntes teóricas, antropológicas e sociológicas estiveram sempre a refletir as religiões como algo "retrógrado". A religião do candomblé criou estratégias de resistência diversificadas, com uma política de negociação e de resultados. $E$ foi guardiã de um pensamento revolucionário. Assim, por exemplo, quando Edison Carneiro, pela sua militância política, estava para ser preso, foi numa casa de candomblé que ele se refugiou por quase seis meses.

$M$ as, se antes era a sociedade dominante, através de algumas instituições, que direcionavam tais políticas contra o candomblé, atualmente nossos inimigos mais perigosos estão nas igrejas pentecostais, fundamentalistas, sobretudo a I greja U niversal do R eino de D eus. H oje elas são nossos grandes inimigos, pois afirmam que as religiões afro-brasileiras, de toda a natureza, são demoníacas.

\section{A posição das outras igrejas}

Estud os A vançAdos - A I greja C atólica não mantém mais aquela posição do passado, não é?

Júlio Santana Braga - Sim, ela evoluiu. Acredito que se tornou mais cristã. Acolhendo a população negra, as irmandades religiosas surgiram como uma estratégia da I greja Católica para controlar os movimentos e as ações dos negros, mas também para convertê-los, a fim de fortalecer as fileiras dos cristãos na Bahia. M as as atividades desenvolvidas pelos negros, dentro de suas irmandades, como a de N ossa Senhora do Rosário dos Pretos, a Sociedade Protetora dos D esvalidos, e tantas outras, iam além do que pretendia o clero. Elas se transformaram em grandes centros de resistência contra-aculturativa e muito da cultura africana, inclusive o sentido profundo de religiosidade do negro, foi preservado. A I greja C atólica não parece ter reagido duramente em relação ao que acontecia e, assim, foi igualmente responsável por um processo de sincretismo religioso que ali se iniciou.

Ademais, ela perdeu esse poder de conversão religiosa. $\mathrm{H}$ oje, não há um enfrentamento da I greja $\mathrm{C}$ atólica com a religiosidade afro-brasileira. 0 contrário sucede com as igrejas fundamentalistas, com as quais há um confronto permanente. I sso porque nessas igrejas há uma declarada vontade de se ocupar espaços, 
utilizando como processo ardiloso a demonização das divindades afro-brasileiras, para depois processar, nas suas famigeradas sessões, o que eles denominam de expurgação desses demônios. Então, agora há uma grande luta, mas mudaram os personagens.

\section{Pesquisas na África}

E STU D OS A VA C ÇA D OS - O senhor é um dos pesquisadores baianos que foram para o continente negro, durante al guns anos, porque havia interesse do Centro de Estudos A fro-O rientais, da U niversidade da Bahia, de manter relações com a África. A preocupação em estimular, aqui no Brasil, os estudos sobre a África era e é correta?

Júlio Santana Braga - Esses estudos têm aspectos positivos e negativos. $\mathrm{N}$ a década de 1960 fui para Benin e na África vivi por quase oito anos. Fui, talvez, o único baiano a efetivamente residir lá, naquela época. Aquela atividade foi valiosa na medida em que se voltou a atenção para o continente matricial. C onhecer as bases dessa matriz foi muito importante, não só pela comparação de uma identidade absurdamente aniquilada. Paralelamente, essa ida de pesquisadores à Á frica significava a recuperação de uma geografia religiosa perdida e fragmentada. H avia, então, a preocupação de entender a dimensão do continente e a importância de sua diversidade cultural. $M$ as essa experiência foi também negativa, porque 0 retorno à África se deu num ponto só do continente africano - em particular na $\mathrm{N}$ igéria e no Benin.

Esse processo teve um caminho único, em vez de diversificarmos a ida a diferentes regiões africanas, relacionadas historicamente com a formação da nossa cultura, concentramo-nos na $\mathrm{N}$ igéria. E m vez de uma re-africanização, ocorreu uma iorubanização, uma nagoização, se não da cultura, talvez de uma memória coletiva. Esquecemos outras matrizes africanas igualmente importantes. Só recentemente tentamos ir a Angola. $M$ as, com a guerra nesse país, não foi possível a permanência ali, assim como o estudo de sua realidade. $\mathrm{N}$ a própria África ocidental não foram pesquisadas várias culturas e no Benin foi estudada apenas a Fon, aqui indistintamente chamada de jêje. Também não nos estendemos para a faixa litorânea da África. Esse foi um aspecto negativo, mas hoje existe uma certa mudança de pensamento, uma vontade de diversificar essas viagens para várias regiões desse imenso continente 